\title{
Status and conservation of the snow leopard Panthera uncia in Api Nampa Conservation Area, Nepal
}

\author{
Gopal Khanal, Laxman Prasad Poudyal, Bishnu Prasad Deviota \\ Rishi RANABHAT and Per Wegge
}

\begin{abstract}
The snow leopard Panthera uncia is globally threatened and reliable information on its abundance, distribution and prey species is a prerequisite for its conservation. In October-November 2014 we assessed the distribution of the snow leopard in the recently established Api Nampa Conservation Area in the Nepal Himalayas. Within selected blocks we conducted sign surveys and counted the number of bharal Pseudois nayaur, its principal wild prey, along transects totalling $106 \mathrm{~km}$. We recorded 203 putative snow leopard signs at an encounter rate of 1.91 signs $/ \mathrm{km}$. Generalized linear models of the number of signs detected per transect showed that elevation had a positive influence and human activities a negative influence on sign encounter rate; prey abundance had only a weak positive influence on sign encounter rate. Within the effectively surveyed area of c. $200 \mathrm{~km}^{2}$, we counted 527 bharal at an estimated density of 2.28 animals $/ \mathrm{km}^{2}$. Recruitment of bharal was low, estimated at $48 \mathrm{kids} / 100$ adult females, most likely a result of poor or overgrazed rangeland. We estimate the total number of bharal in this conservation area to be $>1,000$, a prey base that could sustain 6-9 snow leopards. Based on our field observations, we identified human disturbance and habitat degradation associated with extraction of non-timber forest products, livestock grazing, and poaching as the main threats to the snow leopard. Standardized sign surveys, preferably supplemented by sampling with remote cameras or with genetic analysis of scats would provide robust baseline information on the abundance of snow leopards in this conservation area.
\end{abstract}

Keywords Api Nampa Conservation Area, bharal, Nepal, Panthera uncia, Pseudois nayaur, snow leopard

\footnotetext{
Gopal KHANAL ${ }^{*}$ (Corresponding author) Department of Forests, Ministry of Forests and Environment, Government of Nepal, Singhadurbar Kathmandu, Nepal. E-mail khanal.joshipur@gmail.com

${ }^{*}$ Also at: Centre for Ecological Studies, Lalitpur, Nepal

Laxman Prasad Poudyal and Rishi Ranabhat Department of National Parks and Wildlife Conservation, Ministry of Forests and Environment, Government of Nepal, Kathmandu, Nepal

Bishnu Prasad Devkota Institute of Forestry, Pokhara Campus, Pokhara, Nepal

Per Wegge Faculty of Environmental Sciences and Natural Resource Management, Norwegian University of Life Sciences, Ås, Norway

Received 5 July 2017. Revision requested 15 January 2018.

Accepted 18 January 2018. First published online 30 August 2018.
}

\section{Introduction}

The snow leopard Panthera uncia, although globally 1 threatened, is one of the least studied large mammalian carnivores (Snow Leopard Network, 2014). Its patchy distribution spans c. 2.8 million $\mathrm{km}^{2}$ of high mountains across 12 Asian countries (McCarthy et al., 2016). Based on field studies, extrapolation of density estimates to non-surveyed areas, expert opinion and interviews, the global population is estimated to be $7,446-7,996$, and in 2017 the species was recategorized, from Endangered to Vulnerable, on the IUCN Red List, suggesting that threats to snow leopards have diminished (McCarthy et al., 2017). Nevertheless, burgeoning livestock grazing pressure on its natural prey (Mishra et al., 2004), poaching ( $\mathrm{Li} \& \mathrm{Lu}, 2014$; Nowell et al., 2016), and escalating conflicts with herder communities over livestock depredation (Bagchi \& Mishra, 2006; Suryawanshi et al., 2013) continue to threaten the species. As many as 221-450 snow leopards are killed annually in retaliation by herder communities or as a result of becoming accidentally ensnared in traps set for other species (Nowell et al., 2016). Habitat loss, fragmentation and degradation from infrastructure development (Zaller, 2016), resource extraction (Farrington, 2016) and changing climate patterns (Li et al., 2016) have exacerbated anthropogenic impacts on snow leopard habitat.

In 2013 governments of the snow leopard range countries initiated the Global Snow Leopard Ecosystem Protection Program to combat threats and strengthen transnational collaboration for snow leopard conservation (Snow Leopard Working Secretariat, 2013). Knowledge of the abundance and distribution of the snow leopard across its range is central to the success of the Programme, but reliable information on population status and local threats is unavailable for large parts of the species' range, both within and outside protected areas. Less than $15 \%$ of the species' distribution range has been adequately surveyed (Snow Leopard Network, 2014). As a result, conservation decisions, including those of the Program, are based in part on extrapolations of density estimates to non-surveyed areas. Assessments of snow leopard conservation status in unsurveyed regions across the species' range are thus urgently required for informing management decisions.

The $13,000 \mathrm{~km}^{2}$ of suitable habitat in the Nepal Himalayas has been estimated to support 301-400 snow 
leopards, c. $10 \%$ of the global population (WWF Nepal, 2009). Studies of the snow leopard in Nepal commenced with those of Schaller (1977), Jackson \& Ahlborn (1984), and Jackson (1996) in Shey Phoksundo National Park. Recent studies have focused on the western and central Himalayas (Thapa, 2006; Wegge et al., 2012; Ale et al., 2007, 2014; Devkota et al., 2017), but a large part of potential habitat remains poorly studied, in particular Api Nampa Conservation Area in the western Himalayas.

Reliable estimates of species abundance are fundamental for conservation and management. Recently developed non-invasive techniques, including camera trapping and DNA analysis, are among the best methods to study large elusive carnivores such as the snow leopard (Jackson et al., 2006; Janecka et al., 2008), but are costly. Camera trapping can be logistically challenging when information on presence/absence of the study species is not available. In these circumstances, information on spatial distribution can be useful for defining conservation priorities. The presence and spatial distribution of a species can be assessed based on indirect evidence of species occurrence (e.g. pugmarks, scrapes; Jackson \& Hunter, 1996).

The goal of this study was to determine snow leopard presence and to estimate the abundance of its wild prey in Api Nampa Conservation Area, and thus to estimate the number of snow leopards that this area could potentially support. We also examined the influence of ecological and anthropogenic variables on encounter rate of snow leopard signs.

\section{Study area}

The $1,903 \mathrm{~km}^{2}$ Api Nampa Conservation Area, established in 2010, lies in the far-western Himalayas of Nepal (Fig. 1) at altitudes of 518-7,132 m. Monthly mean maximum temperature is c. $24^{\circ} \mathrm{C}$ in summer and in winter the minimum temperature can drop to c. $-30^{\circ} \mathrm{C}$. Precipitation above 3,500 $\mathrm{m}$ is mainly in the form of snow, which starts to melt in March. Topography is characterized by undulating terrain

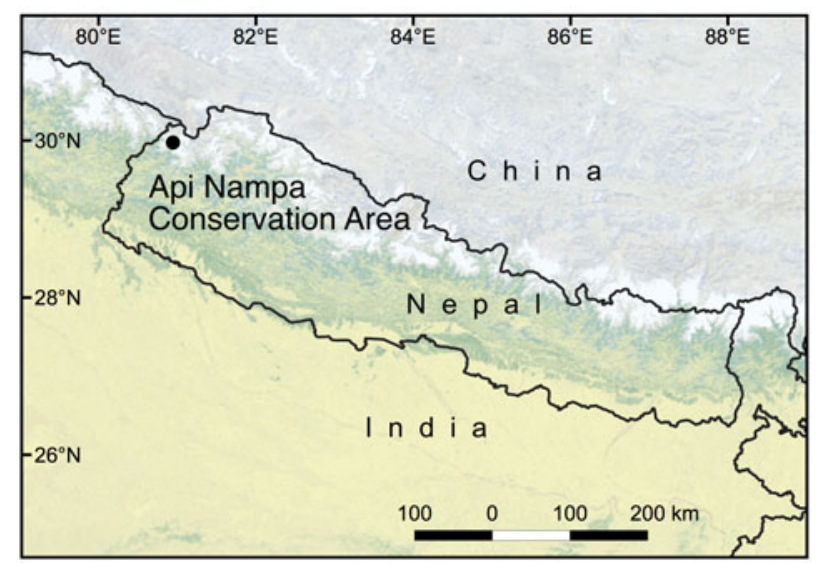

FIG. 1 The location of Api Nampa Conservation Area in Nepal. and river valleys. Vegetation above 3,60o $\mathrm{m}$ is largely dry alpine steppe characterized by meadows rich in sedges and graminoids such as Stipa, Carex and Kobresia. On drier sites and rugged slopes vegetation is dominated by dry grasses and shrubs such as Caragana brevifolia and Lonicera spinosa. Below 3,600 m mixed broadleaved and conifer forest species include blue pine Pinus wallichiana, Himalayan fir Abies spectabilis, birch Betula utilis, burans Rhododendron arboreum, oak Quercus spp. and juniper Juniperus indica. The fauna includes the Himalayan marmot Marmota himalayana, woolly hare Lepus oiostolus, musk deer Moschus chrysogaster, Himalayan goral Naemorhedus goral and bharal (blue sheep) Pseudois nayaur. Bharal is the most common ungulate and a food source for the snow leopard, golden jackal Canis aureus and grey wolf Canis lupus.

Within the suitable habitat for the snow leopard (generally above $3,500 \mathrm{~m}$ ), local communities are mainly agro-pastoralist. Green peas, potato and barley are the main agricultural crops. The dominant source of income for local communities is animal husbandry and collection of non-timber forest products, including a valuable medicinal product that is a complex of the parasitic fungus Cordyceps sinensis and the ghost moth caterpillar Thitarodes spp. (Pant et al., 2017). Livestock species include sheep, goats, yaks, cattle-yak hybrids (dzo, jhopas), and horses. Migratory herders employ a seasonal grazing pattern in which they move large herds of livestock to higher elevations in late April, rotate them among pastures, and then herd them to lower elevations in mid September.

\section{Methods}

\section{Snow leopard sign survey}

We adopted the Snow Leopard Information Management System (Jackson \& Hunter, 1996) to determine snow leopard presence and to estimate the relative encounter rate of snow leopard signs. Although this system was not developed specifically for estimating snow leopard abundance, it is nevertheless a useful method for conducting presence/absence surveys as it is straightforward for field assistants with little formal education to use, has minimal impact on the species being studied, and is inexpensive (Ale et al., 2014). Based on anecdotal information of snow leopard occurrence we selected six study blocks, Tinkar, Nampa, Ghusa, Khandeshowri, Sitaula and Rapla, with areas of $31-50 \mathrm{~km}^{2}$. Within these blocks we located ridgelines, narrow valleys and human trails (used and unused) where snow leopards were most likely to leave signs of territory marking and/or communication (Jackson, 1996), to serve as transects. No routes were surveyed more than once. We recorded the location and sign type (scrape, pugmark, scent marking, scats) with a GPS, and the elevation at the beginning and end of the transect. To quantify potential human 
disturbance on the snow leopard we recorded presence/absence of recent human activities/use of the area (e.g. firewood collection, livestock grazing, snares, poaching camps and fires), as a proxy. A transect was considered to be disturbed if direct evidence for any of these activities was observed at least at one location along the transect. A distance of at least $250 \mathrm{~m}$ was maintained between consecutive transects, to avoid spatial autocorrelation. Transects were at 3,000-5,038 m, nearly all above the treeline. Surveys were conducted in 2014, during October-November, when migratory livestock graze at lower elevations, resident livestock are fed in stalls, and human disturbance is minimal.

\section{Bharal survey}

While conducting sign surveys along transects we also counted bharal using binoculars and spotting scopes (Schaller, 1977; Shrestha \& Wegge, 2008). To determine population structure and recruitment we recorded the age class and sex of each bharal seen. Following Schaller (1977) and Wegge (1979), bharal were categorized as adult males ( $7+$ years old; horns curved and $>45 \mathrm{~cm}$ in length), subadult males (4-7 years; horns curved backwards, with a length of $30-45 \mathrm{~cm}$ ), young males (2-3 years; horn length $15-35 \mathrm{~cm}$ ), adult females ( $>2$ years), yearlings (both sexes, 1-2 years) and young ( $<1$ year). Additional information on group size, particular characteristics and composition of the group (e.g. male groups), location, time and behaviour were recorded for cross checking and to avoid double counting. For the same reason we also surveyed adjacent transects that were within the potential daily movement distance of bharal groups $(5-6 \mathrm{~km})$. Surveys were conducted in 2014, during October-November, when bharal herds congregate for courtship and mating and are therefore easiest to count.

\section{Data analysis}

Density estimates for bharal within each block were calculated by dividing the number of animals recorded by the effectively sampled area (the area covered by scanning from the survey transects). We expected that mean elevation (mean of elevation at beginning and end of transect), prey availability (number of bharal encountered per transect) and human disturbance (presence/absence of recent human activities/use) would influence the sign encounter rate (Wolf \& Ale, 2009; Sharma et al., 2015; Alexander et al., 2016a; Suryawanshi et al., 2017). To test the influence of these potential predictor variables on the number of signs encountered along each transect, we used generalized linear models with a Poisson error distribution and log link function. The predictor variables were standardized to $z$-scores prior to analysis, which allowed us to interpret the model coefficients and to compare effect sizes between alternative models. We assessed collinearity between the predictor variables, using Pearson's correlation coefficients. We did not include covariates that were substantially correlated (Pearson's $|r|>0.7$ ) in the same model (Dormann et al., 2013). We ranked models using the Akaike information criterion adjusted for small samples (AICc; Burnham \& Anderson, 2002). Models with $\triangle \mathrm{AICc}<2$ were considered to be strongly supported by the data. We used the $R$ package $M u M i n$ to perform model averaging of all candidate models (Barton, 2017), and computed 95\% confidence intervals of the beta coefficients for each predictor variable. The model-averaged beta-coefficients of covariates and their 95\% confidence intervals were examined to assess the significance of their effect on leopard sign encounter rate. Confidence intervals that included zero indicated no significant effect of the covariates. The relative importance of each covariate was determined by summing the Akaike weights of the models containing these factors. All analyses were carried out in $R$ 3.4.2 (R Development Core Team, 2017).

We calculated the maximum number of snow leopards that the available bharal population could support following the predator-prey ratio suggested by Oli (1994). We estimated the number of bharal that the suitable snow leopard habitat (c. $600 \mathrm{~km}^{2}$; G. Khanal, unpubl. data) could support based on bharal counts in six blocks (a total of c. $200 \mathrm{~km}^{2}$ ), and then converted the estimated number into biomass. Because there is little reliable empirical information on body weights for each category of bharal, we considered adult male, subadult male, young male, adult female, yearling and young age classes to have a mean weight of 65,60 , $55,55,30$ and $25 \mathrm{~kg}$, respectively (Schaller, 1977). We then used the predator-prey weight ratio $(1: 114-159 ;$ Oli, 1994) to estimate the number of snow leopards that Api Nampa Conservation Area could potentially support. This ratio was based on findings (Jackson \& Ahlborn, 1984) that an adult snow leopard requires $600-900 \mathrm{~kg}$ of meat annually (20-30 bharal) after accounting for energy expenditure in a wild snow leopard and the inedible parts of its prey (Jackson \& Ahlborn, 1984).

\section{Results}

We surveyed 51 transects, covering a total distance of $106 \mathrm{~km}$, with lengths of 900-3,770 $\mathrm{m}$ and a mean length of 2,082 $\mathrm{m}$. We recorded 203 snow leopard signs on 35 transects (Table 1), with a mean encounter rate of 1.91 signs $/ \mathrm{km}$. We excluded scats from the analysis because we were uncertain of identification to species. Scrapes were the most frequently detected sign $(\mathrm{n}=89,0.84 / \mathrm{km})$, followed by pugmarks $(n=67,0.63 / \mathrm{km})$. The highest encounter rate of all types of sign was in the Tinkar block (2.35/km; Table 1$)$.

The predictor variables elevation, human disturbance and prey availability were not highly intercorrelated 
TABLE 1 Results of transect surveys for snow leopard Panthera uncia signs conducted at six sites within Api Nampa Conservation Area (Fig. 1) during October-November, 2014.

\begin{tabular}{|c|c|c|c|c|c|c|}
\hline Site & $\begin{array}{l}\text { Total transect } \\
\text { length }(\mathrm{km})\end{array}$ & $\begin{array}{l}\text { No. of } \\
\text { transects }\end{array}$ & $\begin{array}{l}\text { No. of signs } \\
\text { (per km) }\end{array}$ & $\begin{array}{l}\text { No. of scrapes } \\
\text { (per km) }\end{array}$ & $\begin{array}{l}\text { No. of pugmarks } \\
\text { (per km) }\end{array}$ & $\begin{array}{l}\text { No. of scats } \\
\text { (per km) }\end{array}$ \\
\hline Tinkar & 39.14 & 21 & $92(2.35)$ & $40(1.02)$ & $31(0.79)$ & $16(0.41)$ \\
\hline Nampa & 23.62 & 11 & $43(1.82)$ & $19(0.8)$ & $14(0.59)$ & $8(0.34)$ \\
\hline Ghusa & 20.62 & 8 & $36(1.75)$ & $15(0.72)$ & $12(0.58)$ & $8(0.39)$ \\
\hline Sitaula & 9.57 & 5 & $16(1.67)$ & $8(0.83)$ & $4(0.41)$ & $3(0.31)$ \\
\hline Khandeswori & 5.64 & 3 & $8(1.42)$ & $4(0.71)$ & $3(0.53)$ & $1(0.17)$ \\
\hline Rapla & 7.62 & 3 & $8(1.05)$ & $3(0.39)$ & $3(0.39)$ & $2(0.26)$ \\
\hline Total & 106.21 & 51 & $203(1.91)$ & $89(0.84)$ & $67(0.63)$ & $38(0.35)$ \\
\hline
\end{tabular}

(Pearson correlation coefficients were all $<0.60$ ) and hence all were used in the regression analyses. Elevation was the most important variable in determining the encounter rate of snow leopard signs along transects, followed by a negative effect of human use (Tables $2 \& 3$ ). Snow leopard signs were also positively associated with number of bharal detected from the transect, but the relationship was not statistically significant (Table 3 ).

We counted a total of 527 individual bharal in 32 groups, comprising $30 \%$ males, $38 \%$ females, $14 \%$ yearlings and $18 \%$ young (Table 4), with a mean group size of 16.5 (range 6-48). The highest density of bharal was in the Tinkar block and the lowest in Sitaula, and the greatest numbers of bharal were sighted at 4,000-4,500 m (Fig. 2). The overall density of bharal within the effectively surveyed area of c. $200 \mathrm{~km}^{2}$ was estimated to be $2.28 \pm \mathrm{SE} 0.49 / \mathrm{km}^{2}$. The adult sex ratio was female biased, with 77 males/10o adult females. Overall recruitment rate was 48 young/10o females. The ratio of yearlings to young was $0.83: 1$, indicating a $17 \%$ mortality rate of kids, assuming a stationary age structure and similar recruitment rate to that of the previous 2 years. Approximately $18,100 \mathrm{~kg}$ of bharal biomass was estimated to be available within the effectively sampled area.

This biomass could support 3-4 snow leopards. Based on our occupancy surveys, c. $600 \mathrm{~km}^{2}$ of suitable habitat is available for bharal and snow leopards in Api Nampa. With an estimated density of $2.28 \mathrm{bharal} / \mathrm{km}^{2}$ in the surveyed blocks, we estimate that the suitable habitat $(31 \%$ or $600 \mathrm{~km}^{2}$ of the whole $1,903 \mathrm{~km}^{2}$ protected area) could support a minimum of 1,000 bharal. Considering $40 \mathrm{~kg}$ as the mean weight of an individual bharal, this total population is c. $40,000 \mathrm{~kg}$ of biomass, which, based on the predator-prey ratio (Oli, 1994), could sustain 6-9 snow leopards.

\section{Discussion}

Our study provides the first evidence of snow leopard presence in Api Nampa Conservation Area, Nepal. The information on the estimated number of snow leopards and bharal biomass and density reported here will help in setting up priorities for conservation, research and management.

\section{Snow leopard distribution}

We recorded snow leopard presence in five of the six blocks surveyed. Although the rate at which we encountered snow leopard signs $(1.9 / \mathrm{km}$ for all blocks combined) was lower than reported in other protected areas of Nepal (Kanchenjunga Conservation Area: 5.4 signs $/ \mathrm{km}$, Thapa,

TABLE 2 Poisson regression models describing the occurrence of the snow leopard in Api Nampa Conservation Area (Fig. 1) during October-November 2014, ranked according to the Akaike information criterion adjusted for small sample size (AICc).

\begin{tabular}{|c|c|c|c|c|c|}
\hline Model $^{1}$ & $K^{2}$ & $\mathrm{AICc}$ & $\Delta \mathrm{AICc}^{3}$ & $\operatorname{loglink}$ & $W_{i}^{4}$ \\
\hline Elevation + HumanDist & 3 & 241.47 & 0.00 & -117.48 & 0.62 \\
\hline Elevation + HumanDist + Prey & 4 & 242.46 & 0.99 & -146.79 & 0.38 \\
\hline Elevation & 2 & 252.95 & 11.48 & -124.35 & 0.00 \\
\hline Prey + Elevation & 3 & 254.17 & 12.70 & -123.83 & 0.00 \\
\hline Prey + HumanDist & 3 & 258.27 & 16.80 & -125.88 & 0.00 \\
\hline HumanDist & 2 & 267.10 & 25.63 & -131.43 & 0.00 \\
\hline Prey & 2 & 290.46 & 44.99 & -143.11 & 0.00 \\
\hline Invariant/null & 1 & 305.60 & 64.13 & -151.76 & 0.00 \\
\hline
\end{tabular}

${ }^{1}$ Elevation (m); HumanDist, presence/absence of recent human use of the area; Prey, number of bharal encountered.

${ }^{2}$ Number of parameters.

${ }^{3}$ Difference between the AICc value of the best-supported model and successive models.

${ }^{4}$ Akaike model weight. 
TABLE 3 Model-averaged parameter estimates and 95\% confidence interval describing snow leopard occurrence in Api Nampa Conservation Area (Fig. 1) during October-November 2014.

\begin{tabular}{lclllll}
\hline Parameter $^{1}$ & Estimate $^{2}$ & Adj. SE & Confidence interval & $z$ & $\mathrm{P}$ & Relative variable importance \\
\hline Elevation & 0.12 & 0.02 & $0.08-0.15$ & 4.69 & 0.00 & 1.00 \\
HumanDist & -0.09 & 0.02 & $-0.05--0.13$ & 3.49 & 0.04 & 0.98 \\
Prey & 0.02 & 0.02 & $-0.02-0.06$ & 1.15 & 0.24 & 0.38 \\
\hline
\end{tabular}

${ }^{1}$ Elevation (m); HumanDist, presence/absence of recent human use of the area; Prey, number of bharal encountered.

${ }^{2}$ Averaged from all models.

2006; Sargarmatha National Park: 4.2 signs $/ \mathrm{km}$, Ale et al., 2007; Annapurna Conservation Area: 5.8 signs $/ \mathrm{km}$, Ale et al., 2014; Manaslu Conservation Area: 3.5 signs/km, Devkota et al., 2017), the prey biomass was sufficiently large to support a breeding population of snow leopards. Survey times may influence sign encounter rate. There may be a higher detection rate in winter and post-winter because of accumulation of snow and minimal human presence (Jackson \& Hunter, 1996). Devkota et al. (2017), for example, surveyed both pre-winter (NovemberDecember) and post-winter (May-April). Our surveys, however, were conducted just after the migratory livestock grazing and fungal caterpillar collection season (OctoberNovember). In addition, we did not consider putative snow leopard scats in our analysis, which could have lowered the overall sign encounter rate.

\section{Factors influencing sign encounter rate}

Contrary to our initial expectation, there was only a weak positive association between the availability of bharal and the number of snow leopard signs. Although abundance of wild prey is a key determinant of habitat use and abundance of snow leopards (Sharma et al., 2015; Suryawanshi et al., 2017), it was not the main predictor variable in our study. This could be because the length of the individual transects $(1-2 \mathrm{~km})$ was insufficient to encompass the variability required for the model to detect the relationship, given the wide-ranging nature of snow leopards (Johansson et al., 2016). A temporal mismatch between bharal presence and the time when leopards left signs may also have obscured a direct relationship between the two species. In the Qilian Shan region of China there was a weak association between prey and snow leopard site use at a fine scale ( $16 \mathrm{~km}^{2}$; Alexander et al., 2016b), but a strong positive relationship at a landscape scale (Alexander et al., 2016a). It is also possible that other factors, such as terrain ruggedness, which we could not measure (our sampling units were linear transects and it was not possible to compute a terrain ruggedness index adequately for such features), could have better explained the variability in sign encounter rate, as in Sagarmatha National Park, Nepal (Wolf \& Ale, 2009).

In Api Nampa Conservation Area snow leopards were less likely to leave signs in areas of active human presence. Generally, large carnivores avoid using such areas, especially where hunting or harassment is common (Kerley et al., 2002). In our study area, although illegal resource extraction and hunting are prohibited, local herders disclosed that illegal activities, such as use of snares to hunt bharal and pheasants Lophophorus impejanus, and collection of timber and non-timber forest products, occur frequently. This could be causing significant disturbance to snow leopards. In Sagarmatha National Park snow leopards were less likely to use trails used by tourists, guides or porters and their yak caravans (Wolf \& Ale, 2009).

We were unable to distinguish whether the greater sign encounter rate that we found at higher elevations reflects greater site use or increased sign detection probability as a result of more snow accumulation and greater retention time of signs. Higher elevations are often more remote and less visited by people. A study of the fine scale occurrence of snow leopards in Qilian Shan, China, found that the probability of site use by snow leopards increased with altitude (Alexander et al., 2016a).

TABLE 4 Bharal population structure in Api Nampa Conservation Area (Fig. 1) in October-November 2014.

\begin{tabular}{llllllllll}
\hline Study block & Adult male & Subadult male & Young male & Female & Yearling & Young & Total & Area $\left(\mathrm{km}^{2}\right)$ & Density $^{\left(\mathrm{per} \mathrm{km}^{2}\right)}$ \\
\hline Tinkar & 14 & 20 & 21 & 73 & 27 & 35 & 190 & 50 & 3.8 \\
Nampa & 12 & 12 & 8 & 51 & 16 & 25 & 124 & 40 & 3.1 \\
Ghusa & 15 & 12 & 9 & 39 & 18 & 18 & 111 & 37 & 3 \\
Sitaula & 1 & 1 & 0 & 3 & 2 & 2 & 9 & 15 & 0.6 \\
Khandewori & 7 & 5 & 6 & 21 & 7 & 5 & 51 & 31 & 1.6 \\
Rapla & 6 & 4 & 3 & 15 & 7 & 7 & 42 & 27 & 1.5 \\
Total & 55 & 54 & 47 & 202 & 77 & 92 & 527 & 200 & 2.28 \\
\hline
\end{tabular}




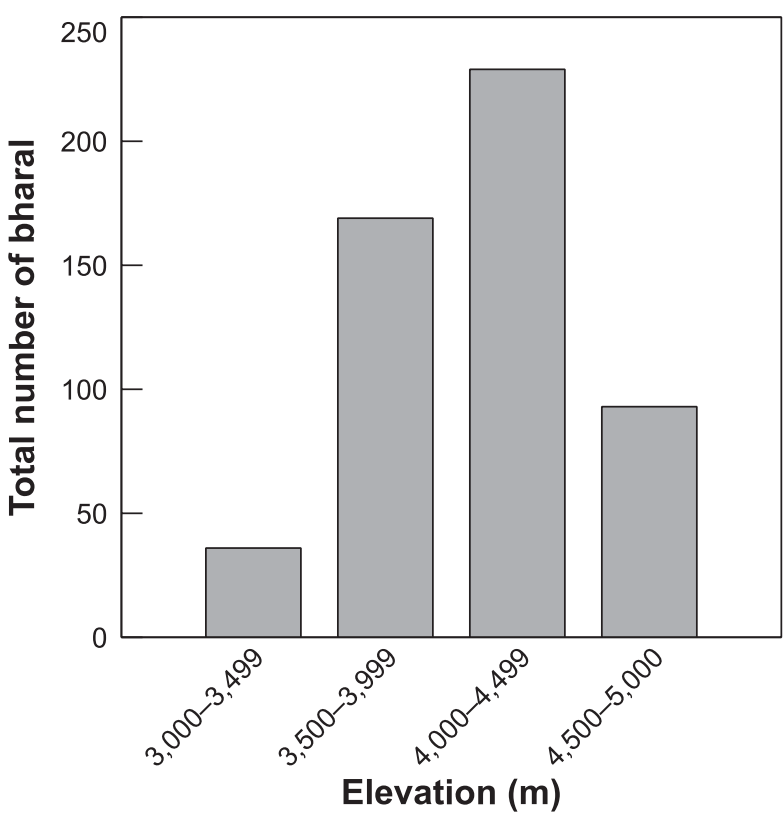

FIg. 2 Total number of bharal Pseudois nayaur observed across four bands of altitude in Api Nampa Conservation Area (Fig. 1) in autumn.

\section{Wild prey bharal density estimates}

Our density estimates and recruitment rate of bharal were lower than in other protected areas in Nepal (Table 5). Schaller (1977) attributed the low recruitment rate in Shey Phoksundo National Park, Nepal, to excessive livestock grazing, but high predation on young animals could also have been a contributing factor. In Spiti Valley, Himachal state, India, high grazing pressure by livestock led to a low bharal reproductive rate (Mishra et al., 2004). However, because of fine-scale habitat partitioning, forage competition between livestock and bharal may not be as direct as commonly assumed (Shrestha \& Wegge, 2008). We did not collect information on habitat relationships or on forage availability but based on our general observations and information on livestock numbers, we suggest that high grazing pressure by seasonally grazing livestock may be a contributing factor to the low recruitment of bharal. Accounts from local community leaders and herders, and data available at the Api Nampa Conservation Area office, suggest that a minimum of 10,000 livestock graze on the rangelands in summer, c. 10x higher than our estimate of 1,00o bharal.

\section{Limitations and further studies}

The information on snow leopard distribution and factors influencing the sign encounter rate reported here are based on limited survey data, and sign encounter rate is a less accurate metric for assessing snow leopard habitat use than movement data from radio telemetry. Our analyses of encounter rates may reflect where we were more likely to detect signs, rather than habitat use per se. Detection of snow leopard signs may be influenced by survey season, search effort, observer experience and fatigue, weather (snow fall), substrate (e.g. snow cover), sign type and longevity, terrain type, site selection (e.g. ridgeline vs river bank trails) and human and livestock use of the area (McCarthy et al., 2008).

Our estimate that 6-9 snow leopards could be supported in Api Nampa Conservation Area is based on the predatorprey ratio (Oli, 1994), which does not take into account the contribution of livestock and alternative prey such as the marmot (Mallon et al., 2016). Livestock can contribute up to $42 \%$ of annual snow leopard diet (Wegge et al., 2012), and smaller mammals such as the marmot can contribute as much as $45 \%$ of the summer food of snow leopards (23\% of annual requirements; Schaller et al., 1988). Although the total prey biomass in the Conservation Area could therefore potentially support more than 6-9 snow leopards, we observed a relatively low abundance of marmots, and local residents indicated there is little livestock depredation by snow leopards. Use of the predator-prey ratio to estimate snow leopard numbers also assumes there is no competition from other predators for the same prey biomass. Because we rarely encountered wolf signs and local herders reported that wolves were seldom observed, it is unlikely that other predators consume a substantial proportion of the bharal biomass.

TABLE 5 Bharal density and population recruitment estimates for Nepal.

\begin{tabular}{|c|c|c|c|c|}
\hline Location & Density (per $\mathrm{km}^{2}$ ) & $\begin{array}{l}\text { Recruitment/young } \\
\text { per } 100 \text { females }\end{array}$ & Year & Source \\
\hline Manang District, Annapurna Conservation Area & $6.6-10.2$ & & 1990 & Oli (1994) \\
\hline Kanchenjunga Conservation Area & 4.2 & 40 & 2006 & Thapa (2006) \\
\hline Shey Phoksundo National Park & 2.1 & 50 & 2006 & Thapa (2006) \\
\hline Phu Valley, Manang & 9.4 & 56 & 2008 & Shrestha \& Wegge (2008) \\
\hline Yak Kharka, Manang & 2.09 & & 2009 & Aryal et al. (2014) \\
\hline Manaslu Conservation Area & 3.8 & & 2011 & Devkota et al. (2017) \\
\hline Annapurna \& Manaslu Conservation Areas & $5.97 \pm \mathrm{SE} 0.10$ & & 2012 & Chetri et al. (2017) \\
\hline Annapurna Conservation Area & 2.3 & 60 & 2013 & WWF Nepal (2013) \\
\hline
\end{tabular}


Our method for surveying the bharal population does not account for imperfect detection and therefore probably underestimated the density of this key prey species, thus also affecting the inference from the predator-prey ratio. The double observer method, which allows the detection probability to be estimated, for correcting the counts, and also allows estimation of the precision of the estimates, could have produced more accurate estimates of the bharal population (Suryawanshi et al., 2012). We counted bharal from transects that often ran along ridgelines. Bharal are wary of disturbance and retreat when they detect humans on ridgelines, even far away. We estimated bharal density by dividing the number of animals seen by the area effectively sampled, which was based on the sum of areas that we considered to have been scanned. This method is subjective and may have overestimated the total sampling area, leading to an underestimation of density. Overall, the potential for underestimation of total prey availability suggests that 6-9 snow leopards is a conservative estimate of the number Api Nampa Conservation Area could support.

Large mammalian carnivores are threatened globally (Ripple et al., 2014; Wolf \& Ripple, 2017), and knowledge of the factors influencing distribution is critical for their conservation. Studying an elusive carnivore such as the snow leopard in remote and rugged terrain is challenging, and using methods such as camera trapping to survey all areas where the species could exist can be costly and logistically difficult. Sign surveys therefore continue to provide evidence for informing conservation decisions and for establishing a baseline for future monitoring. Standardizing the survey protocols (e.g. search effort, observer bias, selection of sampling sites, study season and duration), accounting for imperfect detection in study design and modelling (MacKenzie et al., 2002) and training local herders as citizen scientists and involving them in field surveys could improve the reliability of data from such surveys. For Api Nampa Conservation Area, we suggest that reliable baseline information on snow leopard distribution and abundance be established from standardized sign surveys, preferably combined with camera trapping or genetic studies.

Our field observations and interactions with local communities revealed that human disturbance and habitat degradation associated with extraction of non-timber forest products, livestock grazing, and poaching are major threats to snow leopards in Api Nampa Conservation Area. Conservation awareness campaigns and regulation of natural resource extraction in collaboration with local communities could be crucial in reducing threats to this landscape in general, and to the snow leopard in particular.

Acknowledgements We thank the Department of National Parks and Wildlife Conservation for providing the research permit for this study; The Rufford Foundation, Cleveland Metroparks Zoo and Cleveland Zoological Society for funding the fieldwork; IDEA Wild
Inc., USA, for providing the research equipment; Man Bahadur Khadka, Maheshwar Dhakal, Sher Singh Thagunna, Koustubh Sharma, Hem Raj Acharya, Ashok Kumar Ram, Saroj Panthi, Gokarna Jung Thapa, Pemba Sherpa, Dipendra Nath and Indra Nagari for their support; Rachel Moseley for help in improving the text; and the editor and two anonymous reviewers for their constructive comments.

Author contributions Study design: GK, PW; data collection and analysis: GK; writing: GK, PW, LPP, BPD, RR.

\section{Conflicts of interest None.}

Ethical standards This research abided by the Oryx Code of Conduct.

\section{References}

Ale, S.B., Shrestha, B. \& Jackson, R. (2014) On the status of snow leopard Panthera uncia (Schreber, 1775) in Annapurna, Nepal. Journal of Threatened Taxa, 6, 5534-5543.

Ale, S.B., Yonzon, P. \& ThapA, K. (2007) Recovery of snow leopard Uncia uncia in Sagarmatha (Mount Everest) National Park, Nepal. Oryx, 41, 89-92.

Alexander, J.S., Gopalaswamy, A.M., Shi, K., Hughes, J. \& Riordan, P. (2016a) Patterns of snow leopard site use in an increasingly human-dominated landscape. PLOS ONE, 11, eo155309.

Alexander, J.S., Shi, K., Tallents, L.A. \& Riordan, P. (2016b) On the high trail: examining determinants of site use by the Endangered snow leopard Panthera uncia in Qilianshan, China. Oryx, 50, 231-238.

Aryal, A., Brunton, D., Ji, W. \& Raubenheimer, D. (2014) Blue sheep in the Annapurna conservation area, Nepal: habitat use, population biomass and their contribution to the carrying capacity of snow leopards. Integrative Zoology, 9, 34-45.

BAGCHI, S. \& Mishra, C. (2006) Living with large carnivores: predation on livestock by the snow leopard (Uncia uncia). Journal of Zoology, 268, 217-224.

Barton, K. (2017) MuMIn: Multi-model inference. R package version 1.40.o. Https://cran.r-project.org/web/packages/MuMIn/index.html [accessed 28 March 2017].

Burnham, K.K.P. \& Anderson, D.R.D. (2002) Model Selection and Multimodel Inference: A Practical Information-Theoretic Approach (2nd edition). Springer, New York, USA.

Chetri, M., Odden, M. \& Wegge, P. (2017) Snow leopard and Himalayan wolf: food habits and prey selection in the Central Himalayas, Nepal. PLoS ONE, 12, e0170549.

Devkota, B.P., Silwal, T., Shrestha, B.P., Sapkota, A.P., Lakhey, S.P. \& YADAV, V.K. (2017) Abundance of snow leopard (Panthera uncia) and its wild prey in Chhekampar VDC, Manaslu conservation area, Nepal. Banko Janakari, 21, 11-20.

Dormann, C.F., Elith, J., Bacher, S., Buchmann, C., Carl, G. \& CARrÉ, G. (2013) Collinearity: a review of methods to deal with it and a simulation study evaluating their performance. Ecography, 36, $27-46$.

FARRINGTON, J.D. (2016) Harvesting of caterpillar fungus and wood by local people. In Snow Leopards (eds T.M. McCarthy \& D.P. Mallon), pp. 127-131. Elsevier, New York, USA.

JaCkson, R. \& Ahlborn, G. (1984) A preliminary habitat suitability model for the snow leopard, Panthera uncia. International Pedigree Book of Snow Leopards, 4, 43-52. 
JACKSOn, R.M. (1996) Home Range, Movements and Habitat Use of Snow Leopard (Uncia uncia) in Nepal. PhD thesis. University of London, London, UK.

Jackson, R.M. \& Hunter, D.O. (1996) Snow Leopard Survey and Conservation Handbook, International Snow Leopard Trust Seattle. Fort Collins Science Center, Washington, DC, and U.S. Geological Survey, Denver, USA.

Jackson, R.M., Roe, J.D., Wangchuk, R. \& Hunter, D. (2006) Estimating snow leopard population abundance using photography and capture-recapture techniques. Wildlife Society Bulletin, 34, 772781.

Janecka, J.E., Jackson, R., Yuquang, Z., Diqiang, L., Munkhtsog, B., Buckley-Beason, V. \& Murphy, W.J. (2008) Population monitoring of snow leopards using noninvasive collection of scat samples: a pilot study. Animal Conservation, 11, 401-411.

Johansson, Ö., Rauset, G.R., Samelius, G., McCarthy, T., Andrén, H., Tumursukh, L. \& Mishra, C. (2016) Land sharing is essential for snow leopard conservation. Biological Conservation, $203,1-7$.

Kerley, L.L., Goodrich, J.M., Miquelle, D.G., Smirnov, E.N., Quigley, H.B. \& Hornocker, M.G. (2002) Effects of roads and human disturbance on Amur tigers. Conservation Biology, 16, 97-108.

LI, J. \& LU, Z. (2014) Snow leopard poaching and trade in China 20002013. Biological Conservation, 176, 207-211.

Li, J., McCarthy, T.M., Wang, H., Weckworth, B.V., Schaller, G.B., Mishra, C. et al. (2016) Climate refugia of snow leopards in high Asia. Biological Conservation, 203, 188-196.

MacKenzie, D.I., Nichols, J.D., Lachman, G.B., Droege, S. Royle, J.A. \& Langtimm, C.A. (2002) Estimating site occupancy rates when detection probabilities are less than one. Ecology, 83, 2248-2255.

Mallon, D., Harris, R. \& Wegge, P. (2016) Snow leopard prey and diet. In Snow Leopards (eds T. McCarthy \& D. Mallon), pp. 43-55. Elsevier, New York, USA.

McCarthy, K.P., Fuller, T.K., Ming, M., McCarthy, T.M., Waits, L. \& Jumabaev, K. (2008) Assessing estimators of snow leopard abundance. Journal of Wildlife Management, 72, 1826-1833.

McCarthy, T., Mallon, D., Jackson, R., Zahler, P. \& McCarthy, K. (2017) Panthera uncia. In The IUCN Red List of Threatened Species 2017: e.T22732A5066403o [accessed 3 October 2017].

McCarthy, T., Mallon, D., Sanderson, E. \& Zahler, P. (2016) Biogeography and status overview. In Snow Leopards (eds T. McCarthy \& D. Mallon), pp. 23-41. Elsevier, New York, USA.

Mishra, C., Van Wieren, S.E., Ketner, P., Heitkönig, I.M.A. \& Prins, H.H.T. (2004) Competition between domestic livestock and wild bharal Pseudois nayaur in the Indian Trans-Himalaya. Journal of Applied Ecology, 41, 344-354.

Nowell, K., Li, J., Paltsyn, M. \& Sharma, R.K. (2016) An Ounce of Prevention: Snow Leopard Crime Revisited. TRAFFIC, Cambridge, UK.

Oli, M.K. (1994) Snow leopards and blue sheep in Nepal: densities and predator : prey ratio. Journal of Mammalogy, 75, 998-1004.

Pant, B., Rai, R.K., Wallrapp, C., Ghate, R., Shrestha, U.B. \& RAM, A.K. (2017) Horizontal integration of multiple institutions: solution for yarsagumba related conflicts in the Himalayan region of Nepal? International Journal of Commons, 11, 464-486.

R Development Core Team (2017) R: A Language and Environment for Statistical Computing. R Foundation for Statistical Computing,
Vienna, Austria. Http://www.R-project.org [accessed 15 January 2017].

Ripple, W.J., Estes, J.A., Beschta, R.L., Wilmers, C.C., Ritchie, E.G., Hebblewhite, M. et al. (2014) Status and ecological effects of the world's largest carnivores. Science, 343, 1241484.

Schaller, G.B. (1977). Mountain Monarch: Wild Sheep and Goats of the Himalaya. The University of Chicago Press, Chicago, USA.

Schaller, G.B., Junrang, R. \& Mingjiang, Q. (1988) Status of the snow leopard Panthera uncia in Qinghai and Gansu Provinces, China. Biological Conservation, 45, 179-194.

Sharma, R.K., Bhatnagar, Y.V. \& Mishra, C. (2015) Does livestock benefit or harm snow leopards? Biological Conservation, 190, 8-13.

Shrestha, R. \& Wegge, P. (2008) Wild sheep and livestock in Nepal trans-Himalaya: coexistence or competition? Environmental Conservation, 35, 125-136.

Snow Leopard Network (2014) Snow Leopard Survival Strategy. Revised Version 2014.1. Seattle, Washington, USA.

Snow Leopard Working Secretariat (2013) Global Snow Leopard \& Ecosystem Protection Program Bishkek, Kyrgyz Republic. Http:// www.globalsnowleopard.dreamhosters.com/wp-content/uploads/ 2015/03/GSLEP\%2oFinal\%2oWeb_111313.pdf [accessed 30 July 2018].

Suryawanshi, K.R., Bhatnagar, Y.V. \& Mishra, C. (2012) Standardizing the double-observer survey method for estimating mountain ungulate prey of the endangered snow leopard. Oecologia, $169,581-590$.

Suryawanshi, K.R., Bhatnagar, Y.V., Redpath, S. \& Mishra, C. (2013) People, predators and perceptions: patterns of livestock depredation by snow leopards and wolves. Journal of Applied Ecology, 50, 550-560.

Suryawanshi, K.R., Redpath, S.M., Bhatnagar, Y.V., Ramakrishnan, U., Chaturvedi, V., Smout, S.C. \& Mishra, C. (2017) Impact of wild prey availability on livestock predation by snow leopards. Royal Society Open Science, 4, 170026.

Tнара, K. (2006) Study on Status and Distribution of Snow Leopard and Blue Sheep Including People Interaction: A Case Study From Kanchanjunga Conservation Area, Taplejung and Shey-Phoksundo National Park. Unpublished report. WWF Nepal Program, Kathmandu, Nepal.

WEGGE, P. (1979) Aspects of the population ecology of blue sheep in Nepal. Journal of Asian Ecology, 1, 10-20.

Wegge, P., Shrestha, R. \& Flagstad, Ø. (2012) Snow leopard Panthera uncia predation on livestock and wild prey in a mountain valley in northern Nepal: implications for conservation management. Wildlife Biology, 18, 131-141.

Wolf, C. \& Ripple, W.J. (2017) Range contractions of the world's large carnivores. Royal Society of Open Science, 4, 170052.

Wolf, M. \& Ale, S. (2009) Signs at the top: habitat features influencing snow leopard Uncia uncia activity in Sagarmatha National Park, Nepal. Journal of Mammalogy, 90, 604-611.

WWF Nepal (2009) Estimating Snow Leopard Populations in the Nepal Himalaya. Unpublished report. WWF Nepal, Kathmandu, Nepal.

WW F Nepal (2013) Blue Sheep Monitoring in the Upper Kali Gandaki Valley. Unpublished report. WWF Nepal, Hariyo Ban Program, Kathmandu, Nepal.

ZALLER, P. (2016) Linear infrastructure and snow leopard conservation. In Snow Leopards (eds T.M. McCarthy \& D.P. Mallon), pp. 123-126. Elsevier, New York, USA. 